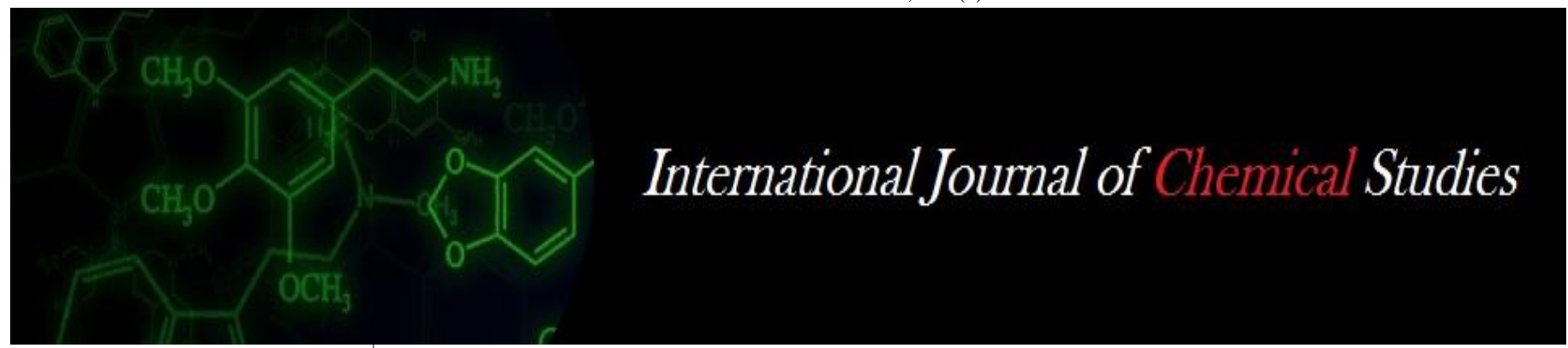

P-ISSN: 2349-8528

E-ISSN: 2321-4902

www.chemijournal.com

IJCS 2021; SP-9(1): 337-342

(C) 2021 IJCS

Received: 09-10-2020

Accepted: 19-12-2020

\section{Rathod BM}

Department of Food Technology,

Vasantrao Naik Marathwada

Krishi Vidyapeeth, Parbhani,

Maharashtra, India

\section{Rathod MS}

Department of Food Technology,

Sant Longowal Institute of

Engineering and Technology,

Department of Food Engineering

and Technology, Longowal,

Punjab, India
Corresponding Author:

Rathod MS

Department of Food Technology,

Sant Longowal Institute of

Engineering and Technology,

Department of Food Engineering

and Technology, Longowal,

Punjab, India

\section{Effect of storage period on the proximate analysis and sensory characteristics of banana chips}

\section{Rathod BM and Rathod MS}

DOI: https://doi.org/10.22271/chemi.2021.v9.i1f.11835

\begin{abstract}
The present investigation for screening of banana (Musa paradisica) cultivars for preparation of banana chips and snacks was carried out to standardize the process for preparation of banana chips and selection of good cultivars for production of Banana chips. Three cultivars viz. Ardhapuri, Grand naine and Mahalakshmi were selected for screening for preparation of banana chips and snacks. Banana slices were fried at different temperature. Three sample Sample A, sample D and sample C from cultivar Ardhapuri, Grand naine and Mahalakshmi respectively were evaluated for textural characteristics which was stored for period 1 month. Textural characteristics evaluated in term of hardness $(\mathrm{kg})$. Low value of hardness indicate that more crispiness. Sample C from Ardhapuri cultivar was low value of hardness it means that it had more crispiness as compared to other samples from cultivar.

Effect of the storage period on the proximate analysis of banana chips was evaluated for three samples which were selected by hydrocolloid treatment. Storage period for 15 days and 30 days were indicating that deflection in the analytical parameter. Moisture content for different samples was increased due to absorption from atmosphere. Fat content was decreased due to formation of free fatty acids which was result in to rancidity. Acidity remains slightaly constant. Ascorbic content were slightly increases. $\mathrm{Ph}$ somewhat remain constant. Peroxide value was increased as the days passes it means indicate that rancidity of oil. Banana snacks prepared were evaluated for sensory characteristics. Sensory characteristics indicate that snacks prepared from Ardhapuri cultivar were good in terms of sensory characteristics as compared to snacks from Grand naine and Mahalakshmi cultivar.
\end{abstract}

Keywords: Frying temperature, sensory characteristics, storage period, banana chips etc.

\section{Introduction}

Fried products are popular as snack foods. These are prepared from a variety of raw materials and vary in size, shape and composition, but all are prepared by deep fat frying in vegetable oils and have relatively large proportions of fat/oil. They have very low moisture content and can therefore be stored under ambient conditions.). Fresh bananas perish rapidly after harvesting and appropriate technology is generally applied to extend its shelf life. Drying extends the shelf-life of a food product because a lack of water prevents microorganisms from growing (Benedict $e t$ al. 1958) ${ }^{[19]}$. Banana (Musa spp.) is an important food crop cultivated widely in tropical and subtropical areas and is one of the major fruits in the world. It was processed widely for various products including banana puree, banana pulp, banana figs, banana flour or powder, banana chips, canned banana slices, banana jam, banana vinegar, banana wine, and banana juice, etc. Application of banana as a medium for LAB fermentation has also been studied (Aegerter and Dunlap, 1980; De Porres et al., 1985) ${ }^{[23,24]}$. All over the world banana is being processed into a wide variety of products namely banana chips, French fries, banana powder and flour, banana cocoa and coffee, alcohol, wine and vinegar. Prospects of banana processing in India are very bright. According to a forecast by Frito-Lay (India), banana processing is expected to increases to 940 tons in 2010. Green banana is very perishable and is subject to very fast deterioration after harvesting. Shyu and Hwang (2001) ${ }^{[6]}$ studied the effects of processing conditions on the quality of vacuum fried apple chips. Consumer acceptance of banana chips is based on quality attributes of the product (Godavari and Narayana, 1969, Wani et al. 2017) ${ }^{[1,2,7]}$. The characteristic crispy texture of potato chips is one of the most important quality indicators of the finished product, apart from colour, odour and flavour. 
Potato chips texture is often described in terms of crispness, hardness and crunchiness. This crispy/crunchy character is an important sensory characteristic on which consumers base their appreciation (A. Salvador 2009) ${ }^{[8]}$. In general, crispness is characterized by a brittle fracture at low fracture force, and distinguishable fracture events, with the concomitant emission of sound (Duizer, 2001; Luyten, Plijter, \& van Vliet, 2004). Vickers $(1987)^{[9,10]}$ related sensory crispness with acoustic attributes of potato chips measured with an oscilloscope and found that measurements indicating the loudness of the sounds correlated most closely with crispness. Duizer (2001) [9] reviewed the main aspects of acoustic research for studying the sensory perception of crisp, crunchy and crackly textures. Srisawas and Jindal (2003) ${ }^{[11]}$ developed a method for evaluating the sensory crispness of snack food products based on direct application of frequency domain spectra of acoustic signals and the use of neural network models; this study measured the perception of air-conducted sounds and their correspondence with the sensation of crispness; the authors concluded that the precise interpretation of acoustic data was difficult (A. Salvador 2009) ${ }^{[8]}$. Raw potato properties as well as manufacturing conditions are important factors determining crispness of potato chips. Segnini, Dejmek, and Oste (1999a) $[12,13]$. highlighted the significance of potato starch content, position of the sample within the tuber, and final moisture content on the texture of potato chips. Pre-drying after blanching was found to decrease oil absorption and to significantly increased crispness of potato chips (Pedreschi \& Moyano, 2005) ${ }^{[14,15]}$. Also, soaking in $\mathrm{NaCl}$ at $25 \mathrm{C}$ for $5 \mathrm{~min}$ after blanching was found to increase crispness (Pedreschi, Moyano, Santis, \& Pedreschi 2007) ${ }^{[14,15]}$. Fat content and texture of potato crisps are also influenced by frying temperature and the type of oil used for frying (Kita, Lisinska, $\&$ Golubowska, 2007) ${ }^{[17,18]}$. Texture of potato chips can be evaluated using sensory and instrumental methods (Szcesniak, Brant, \& Friedman, 1963) ${ }^{[16]}$. Among the instrumental tests, the puncture test placing the entire potato chip in a three-point support has been widely employed. The maximum breaking force was proposed to quantify the texture of the samples (Pedreschi \& Moyano 2005; Pedreschi et al., 2007; Segnini, Dejmek, \& O" ste 1999a, 1999b) ${ }^{[12-15]}$. This fracture force seemed to be a good predictor of all the sensory texture attributes (hardness, crunchiness, chewiness, and tenderness) as measured by a trained panel, while deformation at fracture did not significantly correlate with any of the sensory attributes Segnini et al. (1999b) ${ }^{[12,13]}$. The main causes of spoilage in banana chips are moisture absorption, rancidity, breakage and environmental factors such as oxygen, temperature, light and relative humidity during handling. Shelf-life tests of chips must be related to critical deterioration factors (chemical, physical \& sensory) and in this respect, the problem of moisture absorption is more serious than that of oxygen exposure (Ammawath et al. 2002) ${ }^{[3]}$. Banana chips could play an important role in intervention programs to combat micronutrient deficiencies by virtue of their iron, zinc, and total carotenoid contents.

\section{Materials and Methods \\ Materials}

\section{Collection of banana varieties}

Banana verities were procured from local market and farmers fields. Raw materials for preparation of banana chips were procured from a local market.

\section{Ingredient}

Refined sunflower oil, red chilli powder, salt, packaging material and spices mix were purchased from Parbhani local market.

\section{Chemicals}

Chemicals of analytical grade were obtained from department of Food Chemistry and Nutrition, College of Food Technology, V.N. M.K.V. Parbhani, Maharashtra, India.

\section{Instruments}

All the instruments were used from laboratories of niche area and Dept. of FCN, College of Food Technology, V.N.M.K.V., Parbhani, Maharashtra, India.

\section{Texture profile analysis (TPA)}

\section{Texture profile analysis of banana chips}

Stable Micro System TAXT2 plus Texture Analyzer was used for texture profile analysis (TPA) of banana chips. A ball probe with $5 \mathrm{~mm} / \mathrm{sec}$. of pre-test and post-test speeds; and $50 \%$ compression was taken for TPA analysis. TPA is "two-bite" test, which includes the first and second compression cycles. The first and second compression cycles indicate the force vs. time data during the first and second compression of the product by the instrument probe. Representative graph for texture of banana chips was shown below. The parameters recorded were hardness, cohesiveness, springiness, gumminess and chewiness. Recent trend of consumers towards healthier and low-fat products demonstrated the need to produce novel snacks with good sensory properties (Das et al. 2013) ${ }^{[5]}$.

The test is configured so that the seven TPA parameters, hardness, cohesiveness, springiness and chewiness, were calculated at the time of the test by determining the load and displacement at predetermined points on the TPA curve. Hardness (h,) was the maximum load, expressed in $\mathrm{kg}$, applied to the samples during the first compression. Cohesiveness $(\mathrm{A}, / \mathrm{A}$,$) was the ratio of the area under the curve for the second$ compression (A,) to that under the curve for the first compression (A,). Springiness, expressed as $\mathrm{dJd}$, was the ratio of the duration of contact with the sample during the first compression $(\mathrm{d}$,$) to that during the first compression (\mathrm{d}$,$) .$ Chewiness was the mathematical product of hardness, cohesiveness, and springiness ( $\mathrm{h}, \mathrm{x}$ A / A, $\mathrm{x} \mathrm{d}, / \mathrm{d}$,). There were two replications of the instrumental analysis conducted on two separate days. For each replication, eight individual portions of each of the twenty-one food types were evaluated.

\section{Results and Discussion}

Changes in hardness of optimized banana chips during storage: Texture Measurement of Banana chips was done by TA_XT Texturometer with help of ball probe $0.5 \mathrm{~cm}$ and post speed $20 \mathrm{~mm} / \mathrm{sec}$. Texturel studies was done for fresh sample, sample stored for 15 days and sample stored for 30 days. Hardness value for different banana chips sample was depicated in table 1 .

Hardness value for control sample, sample A-C, sample G-C and sample $\mathrm{M}-\mathrm{C}$ was going to increase. Low value of hardness indicates more crispiness and vice versa. Hardness value was increased due to the absorption of moisture from the environment. Due to this crispiness of banana chips was going to decreased.

Similar results were obtained by Jitra singthong (2009) ${ }^{[20]}$ by Crispiness of banana chipwas evaluated in term of hardness by Texture analyzer (LLOYD texture analyzer model LRSK, UK) with ball probe $0.5 \mathrm{~cm}$ and post speed $20 \mathrm{~mm} / \mathrm{s}$. Low value of hardness indicated high crispiness and vice versa. 
Table 1: Texture Measurement of banana chips by TA_XT Texturometer

\begin{tabular}{|c|c|c|c|}
\hline \multirow{2}{*}{ Samples } & \multicolumn{3}{|c|}{ Hardness $(\mathbf{K g})$} \\
\cline { 2 - 4 } & Fresh & 15 days storage & 30 days storage \\
\hline Control & 0.875 & 0.968 & 0.998 \\
\hline A-C & 1.023 & 1.168 & 1.264 \\
\hline G-C & 1.230 & 1.740 & 1.960 \\
\hline M-C & 1.425 & 1.697 & 1.803 \\
\hline
\end{tabular}

Proximate chemical composition of banana chips: The proximate composition of banana chips was been presented in
Table 2.The data in Table 2 reveals that the moisture content of Grand naine cultivar(3.65\%) was more than Mahalakshmi cultivar (3.61\%) and Ardhapuri cultivar (3.56\%). While Starch content of Ardhapuri cultivar $(33.49 \%)$ was more than Mahalakshmi cultivar $(33.21 \%)$ and Grand naine cultivar $(32.68 \%)$. Fat content of banana chips prepared from Mahalakshmi cultivar. (31.54\%) was slightly more than Ardhapuri cultivar banana chips $(31.21 \%)$ and Grand naine cultivar banana chips $(31.25 \%)$

Table 2: Proximate chemical composition of banana chips

\begin{tabular}{|c|c|c|c|c|}
\hline Sr. No. & Parameter & Ardhapuri & Grand Naine & Mahalakshmi \\
\hline 1. & Moisture (\%) & 3.56 & 3.65 & 3.61 \\
\hline 2. & Starch (\%) & 33.49 & 32.68 & 33.21 \\
\hline 3 & Fat (\%) & 31.21 & 31.25 & 31.54 \\
\hline 4 & Total sugars (\%) & 0.1 & 0.09 & 0.09 \\
\hline 5 & Reducing sugars (\%) & 0.02 & 0.03 & 0.02 \\
\hline 6 & Non-reducing sugars (\%) & 0.08 & 0.06 & 0.07 \\
\hline 7 & Ascorbic acid (mg/100g) & 6.3 & 6.1 & 6.4 \\
\hline
\end{tabular}

Total sugar was also more in Ardhapuri cultivar (0.1\%) than Grand naine $(0.09 \%)$ and Mahalakshmi cultivar $(0.09 \%)$. Total sugar in banana chips includes reducing sugar and nonreducing saugar. Reducing saugar in banana chips prepared from Ardhapuri cultivar was 0.02 per cent while in chips from Grand naine, it was 0.03 per cent and that of Mahalakshmi cultivar chips it was 0.02 per cent. Non reducing sugar was more in banana chips prepared from Ardhapuri cultivar $(0.08 \%)$ than chips from mahalakshmi cultivar $(0.07 \%)$ and Grand naine cultivar $(0.06 \%)$. The ascorbic acid content Ardhapuri cultivar banana chips was $6.30 \mathrm{mg} / 100 \mathrm{~g}$ while Grand naine cultivar was $6.10 \mathrm{mg} / 100 \mathrm{~g}$ and that of Mahalkshmi cultivar was $6.40 \mathrm{mg} / 100 \mathrm{~g}$, Simillar result were obtained by Akubor (2000).

\section{Effect of storage period on the proximate chemical composition of banana chips \\ For Ardhapuri cultivar}

It was revealed on table 3 that moisture content of Ardhapuri cultivar sample A-C is gradually increase i.e. Moisture content for fresh sample was 3.08 per cent, moisture content of stored sample for 15 days was 3.14 per cent while the stored sample for 30 days was 3.29 per cent. Fat content of ardhapuri sample A-C was gradually decreases i.e. For fresh sample it was 32.01 per cent, for stored sample for 15 days was 30.26 per cent while for stored sample for 30 days was 29.46 per cent. Acidity content was remain slightly constant in the range of $0.02-0.01$ per cent.

Table 3: Effect of storage period on the proximate analysis of banana chips. Cultivar-Ardhapuri. Sample A-C

\begin{tabular}{|c|c|c|c|c|}
\hline Sr. No. & Parameter & Fresh & After 15 days & After 30 days \\
\hline 1 & Moisture $(\%)$ & 3.08 & 3.14 & 3.29 \\
\hline 2 & Fat $(\%)$ & 32.01 & 30.26 & 29.46 \\
\hline 3 & Acidity $(\%)$ & 0.02 & 0.01 & 0.01 \\
\hline 4 & Ascorbic acid $(\mathrm{mg} / 100 \mathrm{gm})$ & 15.04 & 14.01 & 13.06 \\
\hline 5 & Ph & 6.06 & 5.97 & 5.96 \\
\hline 6 & Peroxide value $(\mathrm{meg} / \mathrm{kg})$ & 9.93 & 10.07 & 10.69 \\
\hline
\end{tabular}

Ascorbic acid content of Ardhapuri cultivar sample A-C was slightly decreases i.e. for fresh sample it was 15.04 per cent, a sample stored for 15 days it was 14.01 per cent while sample stored for 30 days it was 13.06 per cent. PH for Ardhapuri cultivar of fresh sample a sample stored for 15 days and sample stored for 30 days was 6.06, 5.97 and 5.96 respectively. Peroxide value for Ardhapuri cultivar sample A-C is gradually increases from $9.93 \mathrm{meg} / \mathrm{kg}, 10.07 \mathrm{meg} / \mathrm{kg}$ and $10.69 \mathrm{meg} / \mathrm{kg}$ for fresh sample, sample stored for 15 days and 30 days respectively. Increase in peroxide value indicates that increase rancidity value of oil.

\subsection{For grand naine cultivar}

It was revealed on table 4 that moisture content of Grand naine. Sample G-D was gradually increase i.e. Moisture control for fresh sample was 3.29 per cent, moisture control of sample stored for 15 days was 3.68 per cent while the sample stored for 30 days was 3.79 per cent. Fat content of Grand naine. Sample G-D was gradually decreases i.e. for fresh sample it was 33.06 per cent, for storage sample for 15 days was 31.09 per cent while for sample stored for 30 days was 30.09 per cent. Acidity content was remain slightly constant in the range of $0.03-0.02$.

Table 4: Effect of storage period on the proximate analysis of banana chips. Cultivar-Grand naine. Sample G-D

\begin{tabular}{|c|c|c|c|c|}
\hline Sr. No. & Parameter & Fresh & After 15 days & After 30 days \\
\hline 1 & Moisture (\%) & 3.29 & 3.68 & 3.79 \\
\hline 2 & Fat (\%) & 33.06 & 31.09 & 30.09 \\
\hline 3 & Acidity $(\%)$ & 0.03 & 0.02 & 0.02 \\
\hline 4 & Ascorbic acid $(\mathrm{mg} / 100 \mathrm{gm})$ & 14.09 & 14.01 & 13.96 \\
\hline 5 & $\mathrm{Ph}$ & 6.04 & 5.59 & 5.58 \\
\hline 6 & Peroxide value $(\mathrm{meg} / \mathrm{kg})$ & 9.64 & 10.69 & 11.23 \\
\hline
\end{tabular}


Ascorbic acid content of Grand naine Sample G-D is slightly decreases ie. For fresh sample it was 14.09 per cent, a sample stored for 15 days it was 14.01 per cent while sample stored for 30 days it was 13.96 per cent. pH for Grand naine. Sample G$\mathrm{D}$ of fresh sample, a sample stored for 15 days and sample stored for 30 days was $6.04,5.59$ and 5.58 respectively. Peroxide value for Grand naine. Sample G-D was gradually increases from $9.64 \mathrm{meg} / \mathrm{kg}, 10.69 \mathrm{meg} / \mathrm{kg}$ and $11.23 \mathrm{meg} / \mathrm{kg}$ for fresh sample, sample stored for 15 days and 30 days respectively. Increase in peroxide value indicates that increase rancidity value of oil.

\section{For Mahalakshmi cultivar}

It was revealed on table 5 that moisture content of CultivarMahalakshmi. Sample M-C was gradually increase i.e. Moisture control for fresh sample was 3.06 per cent, moisture control of sample stored for 15 days was 3.17 per cent while the sample stored for 30 days was 3.29 per cent. Fat content of Cultivar-Mahalakshmi. Sample M-C was gradually decreases i.e. for fresh sample it was 32.17 per cent, for storage sample for 15 days was 30.19 per cent while for sample stored for 30 days was 30.01 per cent. Acidity content was remain slightly constant in the range of $0.02-0.01$.

Table 5: Effect of storage period on the proximate analysis of banana chips. Cultivar-Mahalakshmi. Sample M-C

\begin{tabular}{|c|c|c|c|c|}
\hline Sr. No. & Parameter & Fresh & After 15 days & After 30 days \\
\hline 1 & Moisture (\%) & 3.06 & 3.17 & 3.29 \\
\hline 2 & Fat (\%) & 32.17 & 30.19 & 30.01 \\
\hline 3 & Acidity (\%) & 0.02 & 0.01 & 0.01 \\
\hline 4 & Ascorbic acid (mg/100 gm) & 15.06 & 14.99 & 13.07 \\
\hline 5 & $\mathrm{Ph}$ & 6.14 & 5.58 & 5.49 \\
\hline 6 & Peroxide value $(\mathrm{meg} / \mathrm{kg})$ & 9.18 & 10.38 & 11.68 \\
\hline
\end{tabular}

Ascorbic acid content of Cultivar-Mahalakshmi. Sample M-C was slightly decreases i.e. For fresh sample it was $15.06 \%$, a sample stored for 15 days it was $14.99 \%$ while sample stored for 30 days it was $13.07 \%$. pH for Grand naine. Sample G-D of fresh sample, a sample stored for 15 days and sample stored for 30 days was $6.14,5.58$ and 5.49 respectively. Peroxide value for Grand naine. Sample G-D was gradually increases from $9.18 \mathrm{mg} / \mathrm{kg}, 10.38 \mathrm{mg} / \mathrm{kg}$ and $11.68 \mathrm{mg} / \mathrm{kg}$. Increase in peroxide value indicates that increase rancidity value of oil. Similar or less similar result were obtained to Molla et al. (2007) ${ }^{[21]}$.

\section{Effect of storage period on the sensory characteristics of banana chips}

Fresh sample: The sensory scores for colour and appearance, Texture \& Crispiness, Taste, Overall Acceptability of Banana chips in present investigation as Fresh were presented in Table 6.

Table 6: Sensory characteristics of banana chips- fresh

\begin{tabular}{|c|c|c|c|c|c|c|}
\hline \multirow{2}{*}{ Sr. No. } & \multirow{2}{*}{ Treatment } & \multicolumn{5}{|c|}{ Sensory characteristics } \\
\cline { 3 - 7 } & & Colour & Appearance & Texture & Taste & Overall acceptability \\
\hline 1 & Control & 7.0 & 7.0 & 8.0 & 7.0 & 7.0 \\
\hline 2 & A-C & 8.0 & 7.0 & 8.0 & 7.0 & 8.0 \\
\hline 3 & G-D & 6.0 & 6.0 & 6.0 & 7.0 & 6.0 \\
\hline 4 & M-C & 7.0 & 6.0 & 7.0 & 6.0 & 7.0 \\
\hline & Mean & 7.0 & 8.6 & 7.25 & 6.75 & 7.0 \\
\hline & SE & 0.23 & 0.29 & 0.23 & 0.24 & 0.25 \\
\hline & CD at 5\% & 0.68 & 0.75 & 0.75 & 0.76 & 0.77 \\
\hline
\end{tabular}

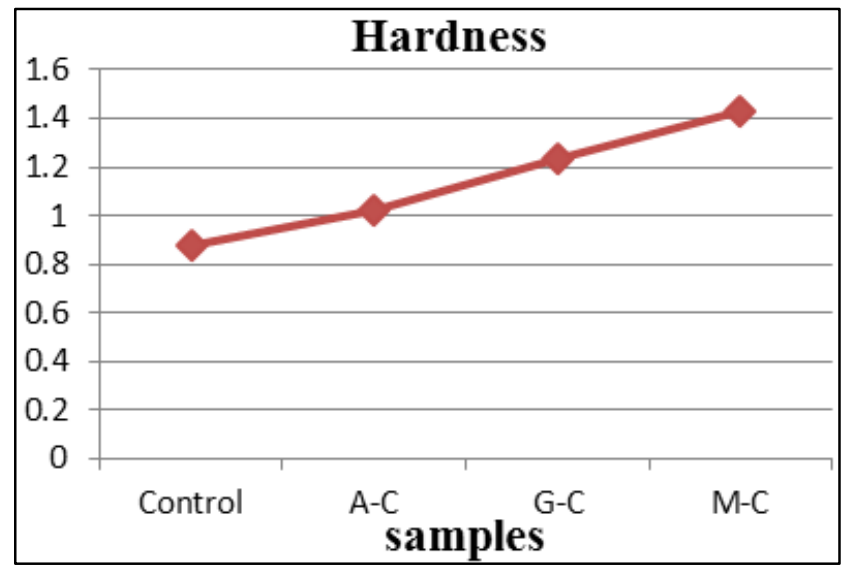

Graph 1: Representative graph of hardness of fresh sample

\section{5 days storage}

The sensory scores for colour and appearance, Texture \& Crispiness, Taste, Overall Acceptability of Banana chips in present investigation as influenced by packaging material and 15 days storage period were presented in Table 7.

Colour score after 15 days was remain same for control sample while that of A-C sample was gradually decreases while for sample G-D and sample M-C remain unchanged. Appearance score for all sample remain unchanged. Textural score for control sample remain same while that of sample A-C was gradually decreases and for sample G-D and M-C was remain unchanged.

Overall acceptability score for control sample remain unchanged while for all other sample was gradually decreases.

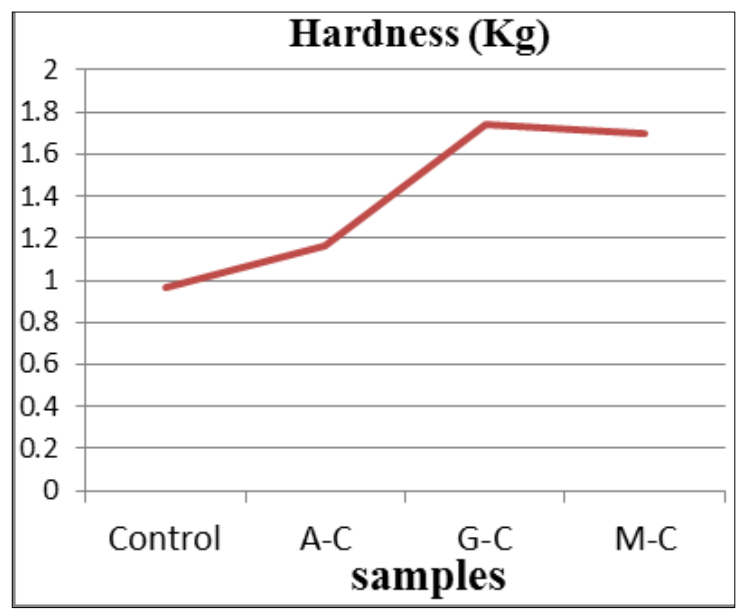

Graph 2: Representative graph of hardness of sample stored for 15 days 
Table 7: Sensory characteristics of 15 days storage banana chips

\begin{tabular}{|c|c|c|c|c|c|c|}
\hline \multirow{2}{*}{ Sr. No. } & \multirow{2}{*}{ Treatment } & \multicolumn{5}{|c|}{ Sensory characteristics } \\
\cline { 3 - 7 } & & Colour & Appearance & Texture & Taste & Overall acceptability \\
\hline 1 & Control & 7.0 & 7.0 & 8.0 & 7.0 & 7.0 \\
\hline 2 & A-C & 7.0 & 8.0 & 7.0 & 8.0 & 7.0 \\
\hline 3 & G-D & 6.0 & 6.0 & 7.0 & 6.0 & 7.0 \\
\hline 4 & M-C & 7.0 & 6.0 & 6.0 & 7.0 & 7.0 \\
\hline & Mean & 6.75 & 6.5 & 6.5 & 6.5 & 7.0 \\
\hline & SE & 0.28 & 0.26 & 0.24 & 0.25 & 0.25 \\
\hline & CD at 5\% & 0.93 & 0.76 & 0.75 & 0.78 & 0.76 \\
\hline
\end{tabular}

\section{0 days storage}

The sensory scores for colour and appearance, Texture \& Crispiness, Taste, Overall Acceptability of Banana chips in present investigation as influenced by packaging material and 15 days storage period were presented in Table 8. Color score after 30 days was remain same for control sample while that of A-C sample was gradually decreases while for sample G-D and sample $\mathrm{M}-\mathrm{C}$ remain unchanged. Appearance score for all samples remain unchanged. Textural score for control sample remain same while that of sample A-C was gradually decreases and for sample G-D and $\mathrm{M}-\mathrm{C}$ was remain unchanged. Overall acceptability score for control sample remain unchanged while for all other sample was gradually decreases.

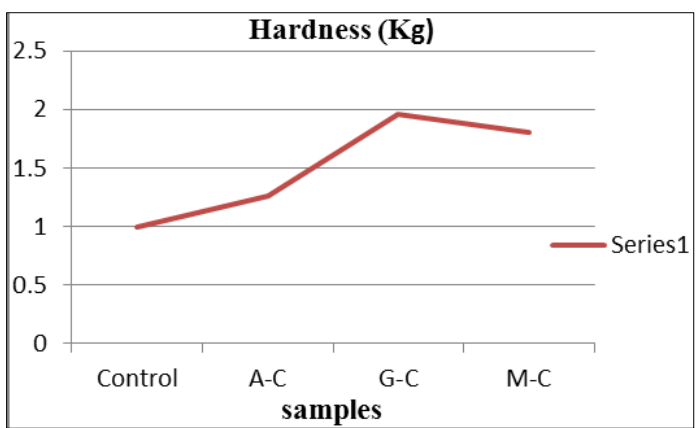

Graph 3: Representative graph of hardness of sample stored for 30 days

Table 8: Sensory characteristics of 30 days storage banana chips

\begin{tabular}{|c|c|c|c|c|c|c|}
\hline \multirow{2}{*}{ Sr. No. } & \multirow{2}{*}{ Treatment } & \multicolumn{5}{|c|}{ Sensory characteristics } \\
\cline { 3 - 7 } & & Colour & Appearance & Texture & Taste & Overall acceptability \\
\hline 1 & Control & 8.0 & 7.0 & 8.0 & 7.0 & 8.0 \\
\hline 2 & A-C & 7.0 & 8.0 & 7.0 & 8.0 & 8.0 \\
\hline 3 & G-D & 6.0 & 6.0 & 6.0 & 6.0 & 6.0 \\
\hline 4 & M-C & 6.0 & 6.0 & 7.0 & 6.0 & 6.0 \\
\hline & Mean & 6.75 & 7.25 & 675 & 6.75 & 7.0 \\
\hline & SE & 0.29 & 0.27 & 0.23 & 0.28 & 0.25 \\
\hline & CD at 5\% & 0.95 & 0.77 & 0.72 & 0.91 & 0.74 \\
\hline
\end{tabular}

Manikantan (2011) ${ }^{[22]}$ was also reported somewhat similar report that the storage stability of banana chips by using polypropylene based non composite packaging films. The effect of nano-composite films on the quality characteristics viz. moisture content (MC), water activity (WA), total color difference (TCD), breaking force (BF), free fatty acid (FFA), peroxide value (PV), total plate count (TPC) and overall acceptability score of banana chips under ambient condition at every 15 days interval were studied for 120 days. All quality parameters of stored banana chips increased whereas overall acceptability scores decreased during storage. The elevation in FFA, BF and TCD of stored banana chips increased with elapse of storage period.

\section{Sensory evaluation of banana snacks}

The Organoleptic evaluation for Banana snacks prepared samples was carried out by a panel of 10 members using a 9 point hedonic scale to assess the parameters like Colour, Taste, Texture, Appearance and Overall acceptability. The average score recorded by judges was presented in table 9 .

Table 9: Sensory evaluation of banana snacks

\begin{tabular}{|c|c|c|c|c|c|c|}
\hline \multirow{2}{*}{ Sr. No. } & \multirow{2}{*}{ Cultivar } & \multicolumn{5}{|c|}{ Sensory characteristics } \\
\cline { 3 - 7 } & & Colour & Appearance & Texture & Taste & Overall acceptability \\
\hline 1 & Control & 8.0 & 8.0 & 8.0 & 8.0 & 8.0 \\
\hline 2 & Ardhapuri & 8.0 & 8.0 & 7.0 & 8.0 & 8.0 \\
\hline 3 & Grand Naine & 7.0 & 7.0 & 7.0 & 7.0 & 7.0 \\
\hline 4 & Mahalakshmi & 7.0 & 6.0 & 7.0 & 7.0 & 7.0 \\
\hline & Mean & 7.25 & 7.0 & 7.25 & 7.25 & 7.25 \\
\hline & SE & 0.24 & 0.26 & 0.23 & 0.24 & 0.29 \\
\hline & CD at 5\% & 0.69 & 0.75 & 0.68 & 0.72 & 0.84 \\
\hline
\end{tabular}

It is observed from table 9 that the highest score for each sensory attributes was recorded in snacks prepared from ardhapuri cultivar followed by control sample whereas minimum score for snacks prepared from mahalakshmi cultivar. Statistically results were significant at 5 per cent $C D$.

\section{Conclusion}

Three sample Sample A, sample D and sample C from cultivar Ardhapuri, Grand naine and Mahalakshmi respectively were evaluated for textural characteristics which was stored for period 1 month. Textural characteristics evaluated in term of 
hardness $(\mathrm{kg})$. Low value of hardness indicate that more crispiness. Sample C from Ardhapuri cultivar was low value of hardness it means that it had more crispiness as compared to other samples from cultivar.

Storage period for 15 days and 30 days were indicate that deflection in the analytical parameter. Moisture content for different samples was increased due to absorption from atmosphere. Fat content was decreased due to formation of free fatty acids which was result in to rancidity. Acidity remain slightly constant. Ascorbic content were slightly increases. $\mathrm{pH}$ somewhat remain constant. Peroxide value was increased as the days passes it means indicate that rancidity of oil.

Banana snacks prepared were evaluated for sensory characteristics. Sensory characteristics indicate that snacks prepared from Ardhapuri cultivar were good in terms of sensory characteristics as compared to snacks from Grand naine and Mahalakshmi cultivar.

\section{References}

1. Godavari Bai S, Narayana Rao MJ. Effect of post-harvest factors on quality attributes of dehydrated banana products. Journal of food science and Technology 1969;6:169-173.

2. Wani SA, Sharma V, Kumar P. Effect of processing parameters on quality attributes of fried banana chips. International Food Research Journal 2017;24(4):14071413.

3. Ammawath W, Che Man YB, Yusof S, Rahman RA. Effects of type of packaging material on physicochemical and sensory characteristics of deep-fat-fried banana chips. J Sci Food Agric 2002;82:1621-1627. DOI: $10.1002 /$ jsfa.1233.

4. Purba Prasad Borah1, Prakash Kumar Nayak. Quality Characteristics of Dried Jahajibanana Chips after Deep Fat Frying. International Journal of Agriculture and Food Science Technology. ISSN 2249-3050 2013;4(9):901-908

5. Das R, Pawar DP, Modi VK. Quality characteristics of battered and fried chicken: Comparison of pressure frying and conventional frying. Journal of Food Science and Technology 2013;50:284-292.

6. Shyu SL, Hwang LS. Effects of processing conditions on the quality of vacuum fried apple chips. Food Research International 2001;34(2/3):133-142.

7. Wani PA, Singh A, Langowski HC. Food Technologies: Packaging Author links open overlay panel Veeranjaneya Reddy Lebaka Venkatarami Reddy Narala Vinod Kumar Joshi Chapter 4 - Development of New Probiotic Foods-A Case Study on Probiotic Juices. Therapeutic, Probiotic, and Unconventional 2018, P55-78.

8. Salvador A, Varela P, Sanz T, Fiszman SM. Understanding potato chips crispy texture by simultaneous fracture and acoustic measurements, and sensory analysis LWT - Food Science and Technology 2009;42:763-767.

9. Duizer L. A review of acoustic research for studying the sensory perception of crisp, crunchy and crackly textures. Trends in Food Science and Technology 2001;12:17-24.

10. Luyten H, Plijter JJ, Van Vliet T. Crispy/crunchy crusts of cellular solid foods: A literature review with discussion. Journal of Texture Studies 2004;35:445-492.

11. Srisawas W, Jindal VK. Acoustic testing of snack food crispness using neural networks. Journal of Texture Studies 2003;34:401-420

12. Segnini S, Dejmek P, Oste R. Relationship between instrumental and sensory analysis of texture and color of potato chips. Journal of Texture Studies 1999;30:677-690.
13. Segnini S, Dejmek P, Oste R. Reproducible texture analysis of potato chips. Journal of Food Science 1999;64(1):309-312.

14. Pedreschi F, Moyano P. Effect of pre-drying on texture and oil uptake of potato chips. LWT - Food Science and Technology 2005;38:599-604.

15. Pedreschi F, Moyano P, Santis N, Pedreschi R. Physical properties of pre-treated potato chips. Journal of Food Engineering 2007;79:1471-1482.

16. Szczesniak AS, Brandt MA, Friedman HH. Development of standard rating scales for mechanical parameters of texture and correlation between the objective and the sensory methods of texture evaluation. Journal of Food Science 1963;28:397-403.

17. Kita A. The influence of potato chemical composition on crisp texture. Food Chemistry 2002;76:173-179.

18. Kita A, Lisinska G, Golubowska G. The effects of oils and frying temperatures on the texture and fat content of potato chips. Food Chemistry 2007;102:1-5.

19. Benedict RG, Corman J, Sharpe ES, Kemp CE, Hall HH, Jackson RW. Preservation of Microorganisms by FreezeDrying. Journal of Applied Microbiology 1958;6:401-407.

20. Jittra Singthong, Chutima Thongkaew. Using hydrocolloids to decrease oil absorption in banana chips LWT - Food Science and Technology 2009;42:1199-203.

21. Molla MM, Alamgir Hossain M, Nasrin T, Sheel S, Islam MN. Study on the preparation of shelf stable ready to serve (RTS) beverages based on bael pulp. Bangladesh Journal of Agricultural Research 2007;32(4):573-586.

22. Manikantan MR, Varadharaju N. Preparation and properties of polypropylene based nanocomposite films for food packaging. Postharvest Biology and Technology 2011;47:407-415.

23. Agerter P, Dunlap C. Cultere of five commonly used acidproducing bacteria on banana pulp. Applied Environmental Microbiology 1980;39(5):937-42.

24. De Porres E, De Arriola MC, Garcia R, Rolz C. Lactic acid fermentation of banana puree, Applied Research Div. Central American Research Institute for Industry lwt, 1985, 18(6). 